\title{
Capsule Commentary on Chretien et al., A Digital Ethnography of Medical Students who use Twitter for Professional Development
}

\author{
Regina Makdissi, MD FACP \\ Division of General Internal Medicine, State University of New York at Buffalo, Buffalo, NY, USA.
}

$\mathrm{J}$ Gen Intern Med 30(11):1701

DOI: $10.1007 / \mathrm{s} 11606-015-3373-8$

() Society of General Internal Medicine 2015

$\mathrm{S}$ ocial media is transforming how our society communicates, and the question of how to incorporate it into medicine is still open. Not surprisingly, clinicians, and particularly younger clinicians, are increasingly engaged in social media. Medical educators are challenged with guiding the medical students and providing them with tools to help with their professional development. The literature has not fully explored the use of social media for educational and career purposes. Chrietien, who has previously published articles on the use of social media, ${ }^{1}$ conducted this ethnographic study of the use of Twitter among medical students. ${ }^{2}$ In this study, Chrietien and colleagues studied the tweets of 31 medical student "superusers" in 2013 and found that Twitter served as a professional tool for these students, giving them access and voice. Students reported tweeting questions and getting answers to clinical questions from international experts within seconds. It also provided added value from the traditional medical school curricula; they gained support, networking, mentoring and learning.

The authors reviewed superusers' posting practices and found that they were aligned with guiding principles of online professionalism and patient privacy. This is critical since compliance with HIPPA regulations is always a concern when using social media. ${ }^{3,4}$ Perhaps the most touching and insightful information in the article was the way the medical students interacted with patients (granted these were patients that the students had not cared for). They felt it gave the patients voice and gave the students insight into patients concerns and experience with their disease. Gaining patient perspective was invaluable to the students' professional development.

Overall this study answered some questions about the use and value of Twitter for certain subgroups of medical students but leaves a lot of answers for future research, such as what is the quality of the learning? How should the medical schools and residency programs manage social media policy? Are there potential negative aspects of Twitter on medical education? How would these students interact if the tweets were with their own patients?

Conflicts of Interest: The author has no conflicts of interest with this article.

Corresponding Author: Regina Makdissi, MD FACP; Division of General Internal Medicine, State University of New York at Buffalo, Buffalo, NY 14215, USA (e-mail: rm49@buffalo.edu).

\section{REFERENCES}

1. Chretien KC, Kind T. Social media and clinical care: ethical, professional, and social implications. Circulation. 2013;127(13):1413-1421.

2. Chretien KC, Tuck MG, Simon M, Singh LO, Kind T. A digital ethnography of medical students who use Twitter for professional development. J Gen Intern Med. doi:10.1007/s11606-015-3345-z.

3. Farnan JM, Snyder Sulmasy L, Worster BK, et al. Online medical professionalism: patient and public relationships: policy statement from the American College of Physicians and the Federation of State Medical Boards. Ann. Intern. Med. 2013;158(8):620-627.

4. American Medical Association. Opinion 9.124 - Professionalism in the Use of Social Media. AMA Code Med Ethics. 2011. http://www.ama-assn.org/ama/ pub/physician-resources/medical-ethics/code-medical-ethics/opinion9124.page. Accessed March 24, 2015. 